\title{
GROWING FAMILIAR
}

\author{
with
}

\section{UNCERTAINTY}

BY CLAIRE CROFTON

\& GRIT WESSER 
These photographs trace a complex portrait of the uncertainty experienced in the occupied West Bank and in Israel. They seek to illuminate the growing normalcy, of what appears to us, a strange reality.
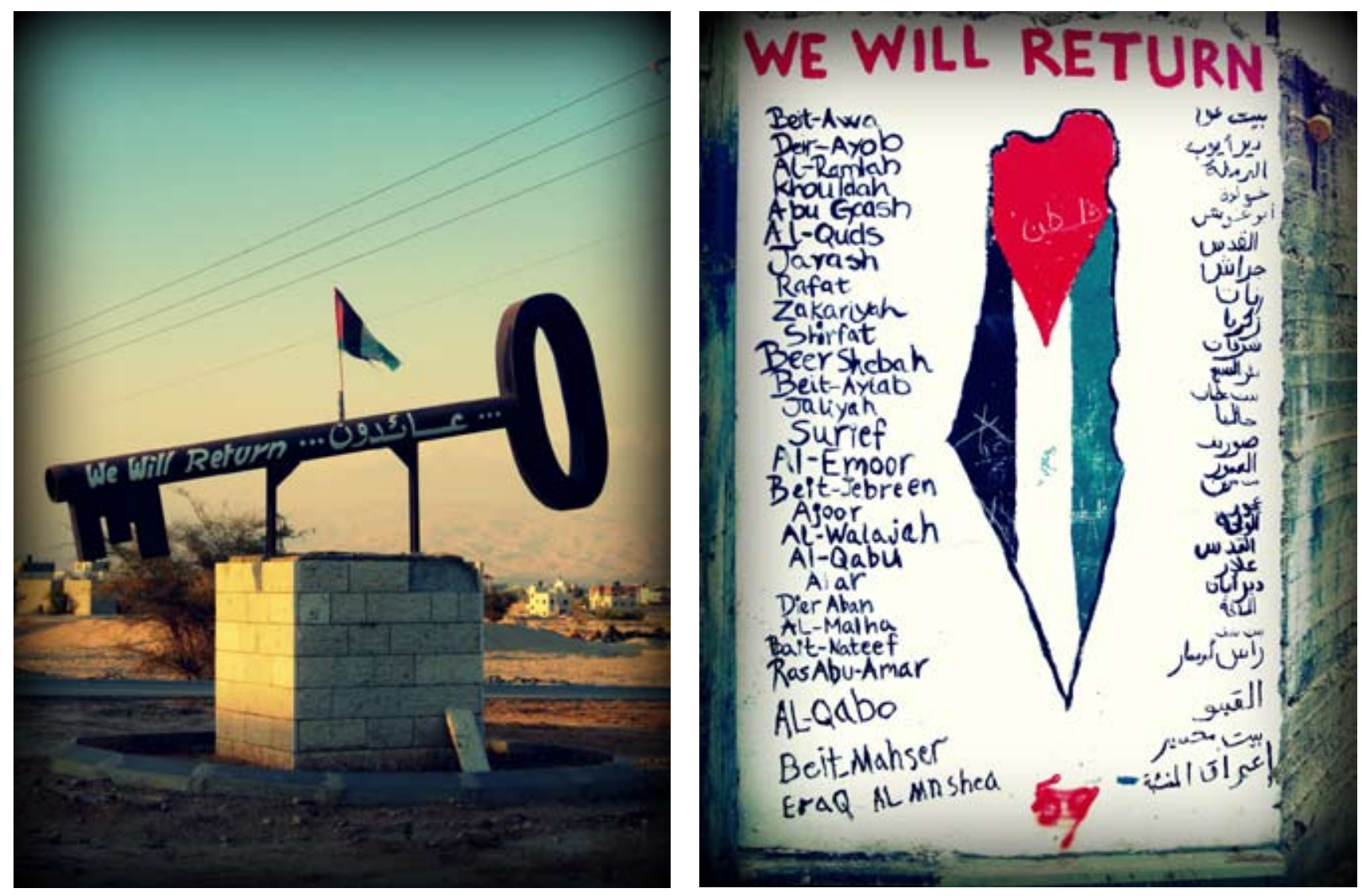

The West Bank is inhabited by 771,000 registered Palestinian refugees, a quarter of whom live in refugee camps ${ }^{1}$. More than sixty years after Palestinians were first evicted from their homes in 1948, it remains uncertain whether their right to return will ever materialise. The key symbolises a hope of return, and also reminds the younger refugees of their families' origins - Photo A (left): outside Aqbat Jaber refugee camp, $3 \mathrm{~km}$ southeast of Jericho. Similarly, the mural in photo B (right) taken in Aida refugee camp, near Bethlehem, lists the villages, now under Israeli control that were once inhabited by Palestinians. Another mural in photo $\mathrm{C}$ (see reverse) depicts features of the more recent Palestinian past, such as housedemolitions, UN aid trucks and journalists. 

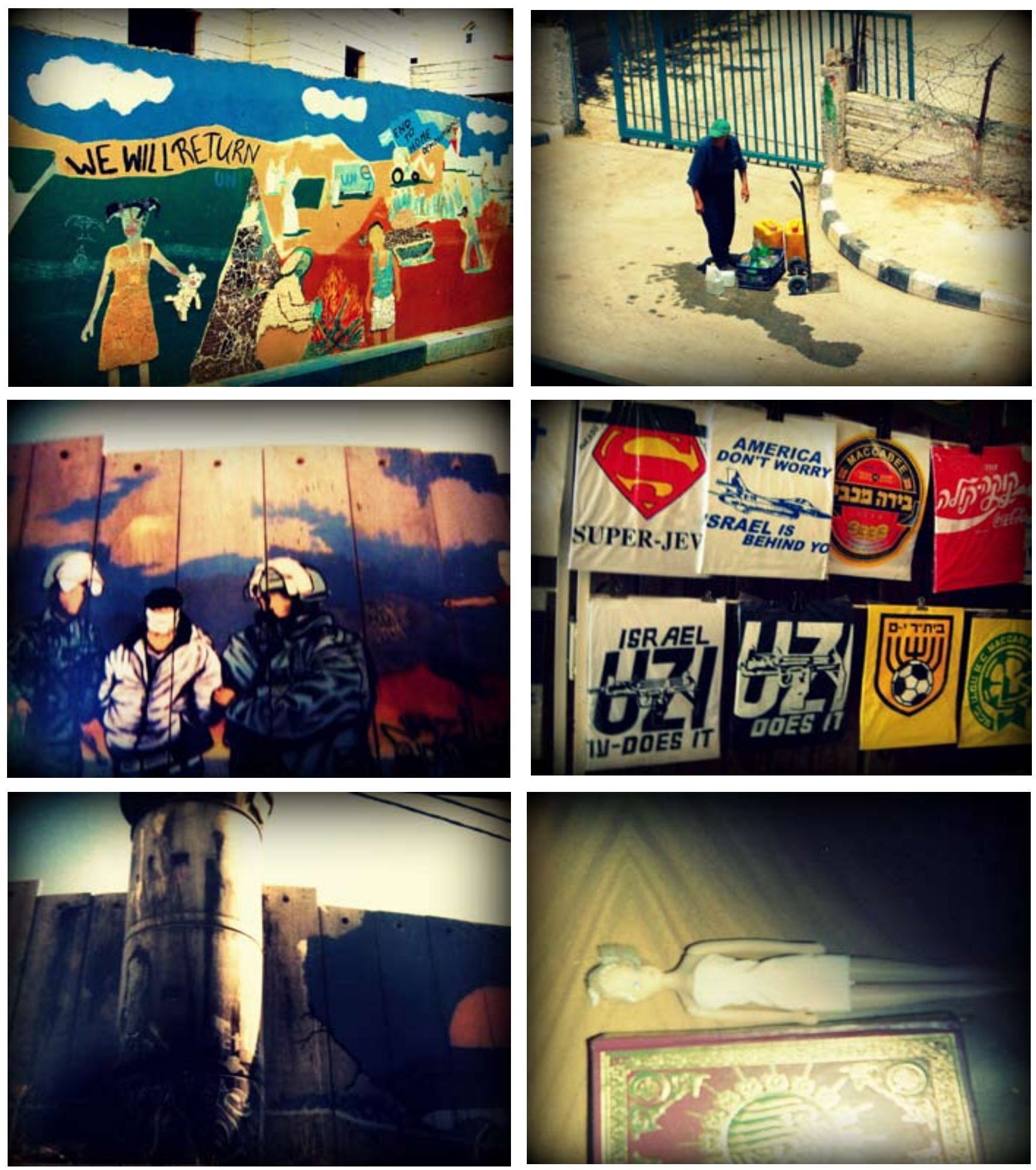

Counterclockwise from top left: photos $C \sim G$ 
The two cultural centres - Lajee and Al-Rowwad - in Aida encourage young Palestinians to channel their frustrations with the occupation through various creative programmes. Photos D-F were taken by Palestinian children as part of a photography workshop run in the summer of 2011 at Al-Rowwad. In this project, children were given disposable cameras and asked to capture aspects of their daily lives. The eerie presence of the separation wall ${ }^{2}$ in so many of these photos reflects the inescapability of the political situation. However, other photos taken in this workshop illustrate more mundane aspects of a childhood lived under occupation.

Palestinians are faced with a plethora of daily uncertainties. High unemployment (43\% in Aida), sporadic water and electricity cut-offs, mid-night raids, security barriers and check points all render daily tasks matters of uncertainty (see Photo F: Elderly man collecting water from a municipal water tap in Aida).

The pervasive presence of the Israeli military exemplifies the insecurity experienced on the other side of the separation wall. T-shirts sold in Acre, Northern Israel sport images and playful jokes on the country's military power (Photo G) illustrate one way in which the conflict has permeated popular culture. The collective memory of the Holocaust is still palpable in both the political and the everyday discourse of Israel $^{3}$, but whether feelings of vulnerability are real or re-imagined as a political tool is uncertain ${ }^{4}$. 佔

1 United Nations Relief and Works Agency for Palestine Refugees 2012: www.unrwa.org

2 The Barrier's total length is approximately $708 \mathrm{~km} .61 .8 \%$ of the Barrier is complete; a further $8.2 \%$ is under construction and $30 \%$ is planned but not yet constructed. When completed, approximately $85 \%$ of its route will run inside the West Bank, isolating g 9.4\% of West Bank territory, including East Jerusalem and No-Man's Land. On 9 July 2004 , the International Court of Justice (ICJ) issued an advisory opinion which stated that the sections of the Barrier route which ran inside the West Bank, including East Jerusalem, violates Israel's obligations under international law.

United Nations Office for the Coordination of Humanitarian Affairs, December 2011: http://www.ochaopt.org/documents/ochaopt atlas_barrier_affecting_palestinians_december2011.pdf

3 Professor Carlo Strenger, The Haaretz, 07.03.2012 http://www.haaretz.com/blogs/strenger-than-fiction/netanyahu-sdangerous-holocaust-analogy-1.417039

4 Ibid. 